\title{
DÜBLIN
}

Technological University Dublin

ARROW@TU Dublin

\section{Human skills assessment as a support to human factor management}

\author{
Lorenzo Comberti \\ Politecnico di Torino, lorenzo.comberti@polito.it \\ Micaela Demichela \\ Politecnico di Torino \\ Maria Chiara Leva \\ Technological University Dublin, mariachiara.leva@tudublin.ie
}

Follow this and additional works at: https://arrow.tudublin.ie/schfsehcon

Part of the Environmental Public Health Commons, Environmental Studies Commons, and the Occupational Health and Industrial Hygiene Commons

\section{Recommended Citation}

Comberti, Lorenzo \& Demichela, Micaela \& Leva, Maria. (2020). Human Skills Assessment as a Support to Human Factor Management. 2650-2655. 10.3850/978-981-14-8593-0_3914-cd.

This Conference Paper is brought to you for free and open access by the School of Food Science and Environmental Health at ARROW@TU Dublin. It has been accepted for inclusion in Conference papers by an authorized administrator of ARROW@TU Dublin. For more information, please contact arrow.admin@tudublin.ie, aisling.coyne@tudublin.ie,gerard.connolly@tudublin.ie.

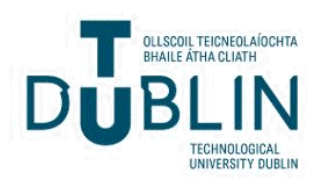




\title{
Human skills assessment as a support to human factor management
}

\author{
Lorenzo Comberti \\ DISAT, Politecnico di Torino, Italy.E-mail: lorenzo.comberti@polito.it \\ Micaela Demichela \\ DISAT, Politecnico di Torino, Italy.E-mail: lorenzo.comberti@polito.it \\ Maria Chiara Leva \\ School of Environmental Health, Technological University Dublin, Ireland,. E-mail: chiara.leva@dit.ie
}

\begin{abstract}
Automatization, robotics and Industry 4.0 are deeply modifying the working condition with an expected reduction of the number of workers employed in traditional job and an increasing request of new professions. Despite these technologies could limit the involvement of workers, in some sectors humans are still widely employed, as in assembly line of manufacturing companies. As a consequence of this, the Human Factor (HF) will still have relevant influence in term efficiency, quality and safety performances.

This paper approached the HF analysis into the manufacturing field in an assembly line. This study was focused on the analysis of those human-skills that are mainly solicited by the workload of the task that a worker has to perform during his own working activity.

A set of practical test was designed and used to measure those skills during the real working activity. Results showed a wide range of performances reflecting different levels of skills between workers. This kind of information can support the human resources management because it allowed a worker classification based on their own skills. This classification can be directly applied to optimize the allocation of workers in assembly line with the using of Human Performance model and it can lead the way to a personalized risk assessment based on personal skills evaluation.
\end{abstract}

Keywords: Human Factor, Human Performance, Human Error, Skills, Safety, Workload.

\section{Introduction}

Emerging technologies are expected to deeply modify the work organisation (Demichela et al., 2017) with relevant impacts on economy, industry and society.

Automatization, robotics, IoT and Big Data are all included in a process called: "Fourth Industrial Revolution". There is a strong novelty represented by this phenomenon compared to previous industrial revolutions. In fact these new technologies are able to combine the physical, digital and even biological worlds, impacting not only on many disciplines from economies to industries but even influencing the concept of Humanity as in Schwab (2016).

One of the most expected effects of this revolution is represented by a dramatic change in the labour market. Several authors have foreseen a strong reduction of the number of workers employed in traditional job with low skills requirements (Acemoglu et al., 2017). This loss of workingplaces would be only partially balanced by an increasing request of new professions related to the new technologies designing, implementation and maintenance (Demichela et al., 2018). This revolution is evolving differentially, in some sector such as in advanced surgery (Finnerty et., 2016) and in automated vehicle driving (Talebian et al., 2018) research and applications are next to be marketed or are already used. In other sectors the diffusion of these technologies seems to have a slower step.

Automotive (Baines et al., 2015) is a sector where the production systems is still based on assembly lines that required a large using of workers. In this situation the Human Resources management or in other words the Human Factor (HF) management has a very relevant impact in several manufacturing branches.

In automotive companies Safety experts are used to take into account the HF into accidents precursor analysis (Comberti et al., 2015) (Baldissone et al., 2019) and into ex-post events analysis (Comberti et al., 2018a) with the aim of reducing their repetition, Quality experts traditionally focused their attention to the connection between the HF and the causes of deviations from procedures where errors are detected (Lin et al., 2001), Work Analysis specialists approached the HF in the field of work organization (Monferini et al., 2013) to reduce 
operational risks (Geng et al., 2015) and to improve work-time optimization.

The relevance of HF in automotive is due to the structure and characteristics of the assemblylines. In fact an assembly line consists in a sequence of working-places where a shell is moved automatically from a workstation to the next following a certain rate called takt-time. In all working-place a task is performed on the shell according to a specific well defined procedure designed to optimize time and costs (Falck et al., 2014). Any task, according to his structure and characteristics, demands to the operator, a different amount of resources for analysing information, recalling items from memory, making decision and manually operate on the shell (Comberti et al, 2019a)

In this configuration the operator, to correctly perform the task, should be able to provide an adequate level of resources (mental, physical...) on the basis of his personal and individual skills. A wrong matching worker-task implies that the operator could have not enough skills to satisfy the requirements of the task. This can increase the probability of human error occurence (Groth et al., 2012) with negative consequences in term of quality and safety (Battaglia et al., 2014).

Considering that the number of working station composing an assembly plant can exceed 200 unit and the number of operators involved can easily exceed 600, the management of process of allocating the operators to the working stations may have strong consequences on the whole production efficiency and on the safety performance (Leva et al., 2017).

In addition to the magnitude of the allocating process there are two further factors to be considered:

- $\quad$ workers of assembly lines are low-skills profile and the management of them is mostly demanded to the personal judgment of the assembly-line supervisor (Comberti et al., 2018b);

- working station requirements are generally knew in qualitative term ( complexity, difficulty) and quantitative (ergonomic stress, saturation time). Workers skills are generally ignored, there is not a system designed to assess their skills and to rank them on the basis of this assessment.

As a consequence of this the workers allocation to the working stations can be considered as key problem for the a plant human resources management.

This paper was intended to give a contribution to the Human Factor Management trough an empirical approach aimed to assess the worker skills. On the basis of this assessment it would be possible to introduce a ranking method useful to identify which worker were more suitable for any single working station of an assembly line.

This work is a part of the validation process of a general framework designed to optimize the matching operator-working station. This framework (Comberti et al., 2019b), named Human Performance model (HPm), was based on an empirical approach able to assess and compare in a common scale both the human skill of a single worker both the resources demanded by any task of a selected assembly line. HPm (Figure 1) was developed with a specific focus on the integration of mental workload concept (Wickens, 2017) with physical workload concept (Punnet et al., 2001).

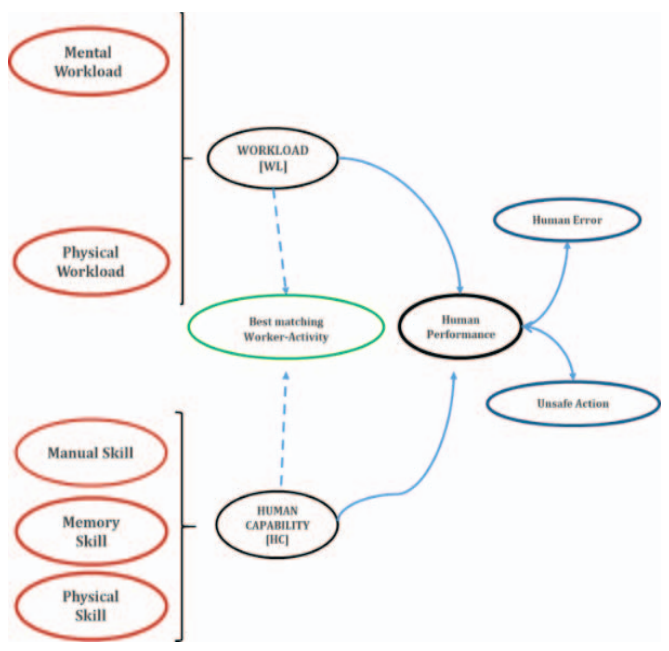

Fig. 1. HPm framework - General scheme

HPm model, resumed in Figure 1, considered that human skill were all included into a factor, named Human capability (HC). HC resumes the resources that the worker can express under the real working condition.

$\mathrm{HPm}$ defined a set of 4 test to be performed by workers during their working activity. Results of the test could be used, according to the model, to assess the HC factor. The design of these tests, customized to be performed during the working activity, represented an innovation of this method in the field of human skill assessment. In fact a large part of the research is still oriented to the physiological measurement (Marszalek et al., 2005) that are not largely replicable in an assembly line because they still need standardized condition to be applied that are far away from a plant condition.

These test have been until now experimented on a small number of workers with promising results. To validate them and to confirm their ability of discerning skills between workers a large survey 
involving more than 100 of an automotive assembly plant have been done.

In this paper the survey methodology and results have been described.

Range of Results highlighted a variety of skills between workers, this information confirmed the importance of the skill assessment as a support for the human factor management.

\section{Material and Methods}

Human Capability (see Figure 1) as mentioned in the previous section, represents the total amount of resources that a worker can offer to execute tasks under given environmental working condition. Literature suggest a large set of human skills that could be solicited performing manual task but considering the purpose of the project and the operational need a set of three ability have been considered as solicited by tasks composing the assembly line.

In particular the human abilities that have been considered were:

-

Manual: skills like precision, manual handling, and coordination are solicited continuously during an assembly task.

- $\quad$ Memory: remembering the sequence of operations and parts to be assembled can differs considerably from task to task.

- Physical: the skill of maintaining a constant performance during the shift and coping with pace.

These variables have been related to the results of 4 empirical test performed by the operators.

Tests have been designed to simulate frequents operations close to the ones performed in the assembly line and to be more linked to human skill tests have to be performed by operators during the working activity. This operation was done with the technical support of plant workanalyst and line supervisor.

The fourth test defined were:

1. Precision test: it consists in moving an iron stick along a not linear contour without touching the borders. This test is related to the manual precision required in many tasks where workers have to assembly components avoiding impact. During this test the time to complete the path and the number of errors were recorded.

2. Both-Hands test. The Work-organisation of the plant promoted the simultaneous using of both hand to perform the task. This was done to minimize the time required to complete the task and to minimize the amount of operator movements. Both-Hands test measure the ability of worker of using both hands to perform simple actions. Time and precision of coordinate movements were recorded.

3. Methodology test. During this test the worker have to decide and to complete a set of simple assembly steps with small parts. Time and errors were recorded.

4. Memory test: sequences of geometric schemes were shown to the worker for few second. The worker was then asked to replicate them on a desktop.

During this test the time to complete the task and its accuracy were recorded.

Tests execution involved directly the operators of the line. To minimize the disturbance to the plant activity a training area was set nearby to the assembly line selected as case study.

In this area the four test were located.

The campaign of test have been anticipated by a single session during which operator received a deep explanation of the project and they could freely try the four test.

This was done to limit any surprise effects on the operator performance.

The tests were planned so as to minimize the impact on the working activity of the assembly line itself and the average time of execution was between 10-12 minutes.

To perform the tests each worker was given a short break, for the time strictly necessary, and replaced by a substitute as it usually happens for any temporary absence.

This configuration allowed the tests to be repeated 3 times during the whole shift for all the workers. All test results showed a good discrimination of workers skills highlighting a wide range of variation in performances.

\section{Results}

Precision, Both-Hand and Methodology test measures 2 quantities: the amount of time spent to complete the test and the number of errors committed during its execution.

Considering the results of each individual skill test, time and errors observed in the text were linearly combined in a common quantity named "Modified Time" (MT) according to the following equation:

$\mathrm{MT}=$ Time$[\mathrm{s}]+$ Errors $\times \mathrm{X}[\mathrm{s}]$

Where:

"Time" was the time recorded to complete the test;

"Errors" was the number of errors observed;

" $X$ " represented a numerical factor with the following value: 
- 3 for the Precision Test;

- 5 for the Both Hand Test;

- 10 for the Method Test.

Memory test measured two quantities: the amount of time to complete the test and a numerical score directly proportional to the accuracy showed by the operator.

Result of Memory test was given as Score divided by time.

On the basis of the method presented in the previous section a data field collection was performed involving 100 workers of an assembly line composed by 40 Working-stations.

The sample of workers was composed by 56 female and 44 male with an average age of 39 years old with no difference between male and female.

Next figures showed results recorded for all test performed.

\subsection{Precision test}

Precision test was the quickest to be completed. Table 1 resumes the average values recorded and Figure 2 reported the results of the Modified Time calculated in accordance to equation 1.

Table 1. Modified Time for Precision Test

\begin{tabular}{|c|c|c|}
\hline $\begin{array}{c}\text { Average Time } \\
{[\mathrm{s}]}\end{array}$ & $\begin{array}{c}\text { Average Errors } \\
\text { [number] }\end{array}$ & $\begin{array}{c}\text { Modified Average Time } \\
{[\mathrm{s}]}\end{array}$ \\
\hline 31,4 & 4.1 & 43,8 \\
\hline
\end{tabular}

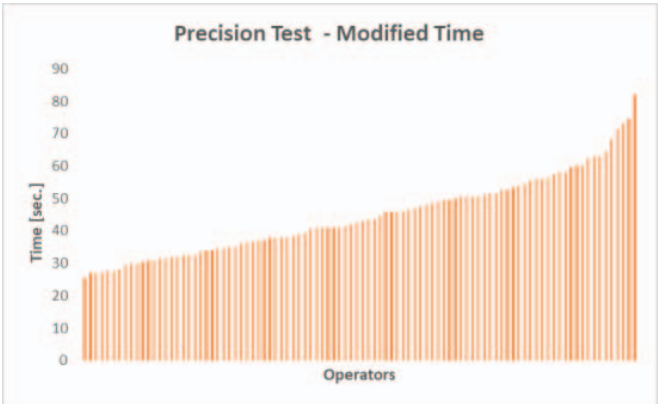

Fig. 2. Precision Test Results

Figures 2 highlights the capacity of the Precision test of discriminating between different skilllevels among workers.

In fact The Modified Time (MD) assessment revealed a wide range of performance variation, from a minimum of 21 second to a maximum of 80 second.

The average value was 43.8 second and this highlights in comparison to the minimum and the maximum values how relevant could be the difference in term of performance from operator to operator.

\subsection{Both-Hand test}

This test was the longest to be performed. It consisted in a series of simple operation to be performed using both hands contemporary. This was done because the procedure that operators have to respect performing their own task have been designed to save time and avoid not necessary movements.

To guarantee this objectives all these procedures impose to workers the contemporary both hand using.

Table 2 resumes the average values recorded and Figure 3 reported the results of the Modified Time calculated in accordance to equation 1 for all the operators involved.

Table 2. Modified Time for Both Hand Test

\begin{tabular}{|c|c|c|}
\hline $\begin{array}{c}\text { Average Time } \\
{[\mathrm{s}]}\end{array}$ & $\begin{array}{c}\text { Average Errors } \\
\text { [number] }\end{array}$ & $\begin{array}{c}\text { Modified Average Time } \\
{[\mathrm{s}]}\end{array}$ \\
\hline 102 & 7 & 138 \\
\hline
\end{tabular}



Fig. 3. Both Hand Results

Figures 3 highlights the capacity of the BothHand Test test of discriminating between different skill-levels among workers.

In fact The Modified Time (MD) assessment revealed a wide range of performance variation, from a minimum of 70 second to a maximum of more than 300 seconds.

The average value was 102 second and this highlights in comparison to the minimum and the maximum values how relevant could be the difference in term of performance from operator to operator.

\subsection{Method test}

This test consisted in a set of small components (Screws, nuts, washers) to be assembled in several configuration following written instruction. 
Workers were free to adopt their own method to assembly all parts in 6 different configuration.

Errors were represented by configuration not correspondent to those described into the instruction.

Table 3 resumes the average values recorded and Figure 4 reported the results of the Modified Time calculated in accordance to equation 1 for all the operators involved ordered by the minimum value recorded to the maximum one.

Table 3. Modified Time for Precision Test

\begin{tabular}{|c|c|c|}
\hline $\begin{array}{c}\text { Average Time } \\
{[\mathrm{s}]}\end{array}$ & $\begin{array}{c}\text { Average Errors } \\
{[\text { number] }}\end{array}$ & $\begin{array}{c}\text { Modified Average Time } \\
{[\mathrm{s}]}\end{array}$ \\
\hline 86 & 1 & 96 \\
\hline
\end{tabular}

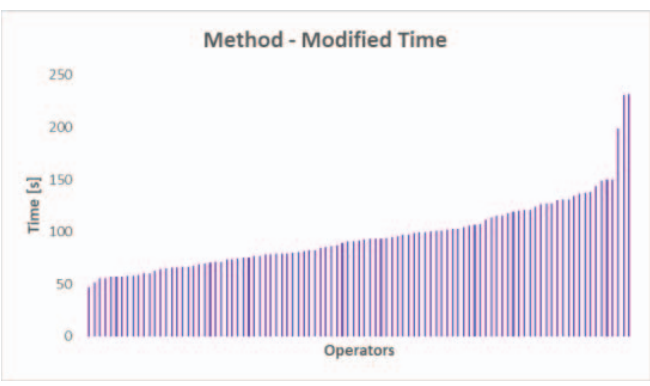

Fig. 4. Method Test Results

Figures 4 highlights the capacity of the Method Test of discriminating between different skilllevels among workers. In fact The Modified Time (MD) assessment revealed a wide range of performance variation, from a minimum of 50 second to a maximum of more than 230 seconds. The average value was 96 seconds.

\subsection{Memory test}

This test was designed to assess the memory capacity that is strongly recalled during the working activity for remembering the sequence of operations and parts to be assembled that can differs considerably from task to task.

In this case the values recorded were Time and Score that was proportional to the percentage of correct remembered configurations.

Table 4 resumes the average values recorded and Figure 5 reported the results of the Score/Time for all the operators involved ordered by the minimum value recorded to the maximum one.



Fig. 5. Memory Test Results

In this case the best result was the one with the highest value of Score/Time because it represented a larger amount of correct remembered frame par second.

Figures 5 highlights the capacity of the Memory Test of discriminating between different skilllevels among workers. In fact Score/Time assessment revealed a wide range of performance variation, from a minimum of 70 to a maximum of more than 200.

\section{Discussion and Conclusion}

All tests performed highlighted a large range of results confirming the capacity of these tests of distinguish the personal skills of the workers involved.

Some workers reported good performance in some tests and bad performance in other, as an example a couple of workers had very good results in Memory test and medium results in Precision and Both Hand tests.

This kind of information suggested of allocating them to those working-station demanding high memory requirements and lower manual requirements.

This information can help any human resources allocation problem providing a quantification of the workers skills.

The number of operators involved, greater respect past experience that involved at maximum 25 operators, allowed a numerical validation of these tests as they have been set and applied.

This is a relevant result for HPm method because it proves his feasibility in real operative condition with relevant number of workers involved.

\section{References}

Acemoglu, D.; Restrepo, P.; (2017), Concluding remarks. In Robots and jobs: evidence from
Table 4. Modified Time for Precision Test

\begin{tabular}{|c|c|c}
\hline $\begin{array}{c}\text { Average Time } \\
{[\mathrm{s}]}\end{array}$ & $\begin{array}{c}\text { Average Score } \\
\text { [number] }\end{array}$ & $\begin{array}{c}\text { Score/Time } \\
1 /[\mathrm{s}]\end{array}$ \\
\hline 162 & 21440 & 135 \\
\hline
\end{tabular}


US labor markets, 2nd ed.; NBER Working paper series, Eds.; NATIONAL BUREAU OF ECONOMIC RESEARCH: 1050 Massachusetts Avenue Cambridge, MA 02138 March 2017; Working Paper 23285, pp. $1-37$.

Baines, T.S.; Asch, R.; Hadfield, L.; Mason, J.P.; Fletcher, S.; Kay, J.M., (2005), Towards a theoretical framework for human performance modelling within manufacturing systems design. Simulation Modelling Practice and Theory, 2005, 13(6), 451-524.

Baldissone, G.; Comberti, L.; Bosca, S.; Murè, S. (2019), The analysis and management of unsafe acts and unsafe conditions. Data collection and analysis. Safety Science, 119, 240-251, DOI: 10.1016/j.ssci.2018.10.006

Battaglia, M., Frey, M., Passetti, E., (2014). Accidents at work and costs analysis: Afield study in a large italian company. Industrial Health 2014 jul; 52(4).

Comberti L., Baldissone, G., Bosca, S., Demichela, M., Murè, S., Petruni, A., Djapan, M., Cencetti, S. Comparison of two methodologies for occupational accidents precursors data collection, ESREL (2015), pp. 3237-3244, Zurich, Swizerland.

Comberti, L.; Demichela, M., Baldissone, G.; Fois, G., Luzzi, R., (2018a), Large occupational accidents data analysis with a coupled unsupervised algorithm: the S.O.M. K-means method. An application to wood industry. $\begin{array}{llll}\text { Safety } & 4(4) & 51 & \text { DOI: }\end{array}$ 10.1016/j.ssci.2018.03.014.

Comberti L., Demichela M., (2018b), Human factor assessment in assembly line: an operative model, Chemical Engineering Transactions, 67, 109-114

Comberti, L.; Baldissone, G.; Demichela, M.; An empirical approach to workload assessment for process optimization. (2019a), Chemical Engineering Transactions, 76, 109-114

Comberti, L., Leva, M.C., Demichela, M., Desideri, S., Baldissone, G., Modaffari, F., (2019b), An Empirical Approach to Workload and Human Capability Assessment in a Manufacturing Plant. In International Symposium on Human Mental Workload: Models and Applications. 2019. Springer, cham 180-201.

Demichela, M., Baldissone, G., Camuncoli, G., (2017), Risk.Based decision Making for the Management of Change in Process plants: Benefits of integrating probabilistic and phenomenological analysis. Industrial and engineering chemical Research, 56(50, pp. 14873-14887..

Demichela, M., Baldissone, G., Darabnia, B., (2018), Using field data for energy efficiency based on maintenance ad operational optimisation. A step towards PHM in process plants. Process, 6(3), 25.

Falck, A. C., R. Örtengren, M. Rosenqvist. (2014), Assembly Failures and Action Cost in Relation to Complexity Level and Assembly Ergonomics in Manual Assembly (Part 2). Interna-tional Journal of Industrial Ergonomics (44), 455-45.(2014)

Finnerty, B.M., Afaneh, C., Aronova, A. et al. Surg Endosc, (2016) 30: 567.

Geng, J.; Mure, S.; Baldissone, G.; Camuncoli, G.; Demichela, (2015), M. Human Error Probability Estimation in ATEX-HMI Area Classification: From THERP to FUZZY CREAM. Chem. Eng. Trans. 2015, 43, 12431248

Groth K.M., Mosleh, A., A data-informed PIF hierarchy for model - based Human Reliability Analysis. Reliability Engineering and System Safety 108, 154-174 (2012)

Leva, M. C., Comberti, L., Demichela, M. \& Duane, R. (2017). Human performance modelling in manufacturing: mental workload and task complexity. H-Workload 2017: The first international symposium on human mental workload, Dublin Institute of Technology, Dublin, Ireland, June 28-30.

Lin, L., Drury, C.G., S.-W. Kim., (2001)Ergonomics and Quality in Paced Assembly Lines. Human Factors and Ergonomics in Manufacturing 11, 377-382 (2001). DOI: 10.1002/hfm.1020

Marszalek, A., Konarska, M., Bugajska, J., (2005), Assessment of work ability in a hot environment of workers of different ages. International Congress Serie 1280, (2005), 208-213

Monferini, A.; Konstandinidou, M.; Nivolianitou, Z.; Weber, S.; Kontogiannis, T.; Kafka, P.; Kay, A.M.; (2013), Leva, M.C.; Demichela, M. A compound methodology to assess the impact of human and organizational factors impact on the risk level of hazardous industrial plants. Reliab. Eng. Syst. Saf. 2013, 119, 280 289

Punnett, L., Fine,L.J., Keyserling, W. M., Herrin, G. D., Chaffin, D. B., Shoulder Disorders and Postural Stress in Automobile Assembly Work. Scandinavian Journal of Work, Environment \& Health 26, 283-291 (2001)

Schwab, Klaus. (2016) "The Fourth Industrial Revolution." (2016).

Talebian, A., Sabyasachee, M., (2018), Predicting the adoption of connected autonomous vehicles: A new approach based on the theory of diffusion of innovations. Transportation Research Part C 95 (2018) 363-380.

Wickens, C. D. (2017, June). Mental workload: assessment, prediction and consequences. In International Symposium on Human Mental Workload: Models and Applications (pp. 1829). Springer, Cham. 